\title{
CONSTRUCCIÓN TEATRAL DE DOS ALMAS CAUTIVAS VESTIDAS DE PIELES: SEGISMUNDO Y ASTOLFO ${ }^{1}$
}

\author{
Kimberly Rojas Ramírez \\ (Universidad Complutense de Madrid) \\ kimrojas@,ucm.es
}

\section{RESUMEN}

A falta de una edición crítica ${ }^{2}$ y de otros estudios pormenorizados sobre la materia textual y teatral de la comedia Las Amazonas, de Antonio de Solís, este trabajo pretende realizar un primera aproximación mediante el análisis de la construcción de la conducta teatral de su personaje principal, Astolfo, tomando como punto de partida la convicción de que existen correspondencias diversas entre este y el que Calderón de la Barca configura para protagonizar la obra cumbre de su producción dramática, Segismundo, de La vida es sueño. Se tratarán de desentrañar los puntos de conexión entre ambos, a la luz del conjunto de elementos teatrales, literarios y epistemológicos con los que se configura la personalidad de los personajes, respectivamente, y de las sutilezas propias de cada dramaturgo.

PALABRAS CLAVE: Teatro Siglos de Oro; Calderón de la Barca; Antonio de Solís; Las Amazonas; espacio dramático.

\section{THEATER CONSTRUCTION OF TWO CAPTIVE SOULS CLOTHED IN FURS: SEGISMUNDO AND ASTOLFO}

\begin{abstract}
In the absence of a critical edition and other detailed studies on the textual and theatrical dimension of the comedy Las Amazonas, by Antonio de Solís, this work aims to make a first approach by analyzing the construction of the theatrical behavior of its main character, Astolfo, taking as a starting point the conviction that there are diverse correspondences between this and the one that Calderón de la Barca configures to star in the masterpiece of his dramatic production, Segismundo, of La vida es sueño.

\footnotetext{
${ }^{1}$ Este trabajo se inscribe en el marco del proyecto de investigación Fiestas teatrales en el Coliseo del Buen Retiro (1650-1660): Catalogación, estudio, edición crítica y recreación virtual, financiado por el Ministerio de Ciencia, Innovación y Universidades con la referencia PGC2018-098699-B-I00.

${ }^{2} \mathrm{La}$ cual se encuentra en vías de elaboración a cargo del mencionado proyecto.
} 
We will try to unravel the points of connection between the two, taking into account of the set of theatrical, literary and epistemological elements with which the personality of the characters is configured, respectively, and of the subtleties of each playwright.

KEY WORDS: Spanish Golden Age Theatre; Calderón de la Barca; Antonio de Solís; Las Amazonas; dramatic space.

En su edición de las Comedias de Antonio de Solís de 1984, Sánchez Regueira ${ }^{3}$ señaló la necesidad que hay de contribuir a que Solís se consagre y aparezca en las historias de la literatura como un autor de primera categoría, puesto que su obra no es dependiente, ni tampoco un apéndice, en absoluto, de la producción literaria calderoniana. Antonio de Solís es contemporáneo a Calderón. No obstante, es importante tener en cuenta que aunque represente una tendencia más moderna, la obra dramática de Solís no va más allá de 1660, momento en el que Calderón aún no ha abandonado el campo escénico español ${ }^{4}$. Sabemos que Calderón y Solís «fueron amigos y vivieron en los mismos ambientes ${ }^{5}$, incluso, colaboraron juntos con Antonio de Coello para la composición de Elpastor Fido. Durante el siglo XVII, la obra de Solís alcanzó una fama tan favorable como la que gozaron los mayores dramaturgos de su tiempo y ya «en la década de los años cincuenta, se le consideraba en la Corte tan merecedor como Calderón» ${ }^{6}$. Aunque fue su Historia de la Conquista de México la obra que mayor éxito e impresiones alcanzó, el resto de su producción no dejó de recibir grandes elogios y el respeto de personalidades tan distinguidas como el propio Calderón, Rodrigo Méndez Silva, Juan de Goyeneche, el padre Feijoo, Eugenio de Ochoa o Martínez de la Rosa. En palabras de Mesonero Romanos, Antonio de Solís demuestra que «su peregrino talento, su exquisita instrucción y su gusto cultivado le permitían cruzar las armas de su ingenio con aquellos admirables modelos», es decir, Calderón y Moreto ${ }^{7}$. Una prueba fidedigna de todo ello son, «en el estilo heroico, sus comedias de Eurídice y Orfeo, Triunfos de amor y fortuna, Las Amazonas y sobre todo la de El alcázar del secreto, en las cuales acertó a imitar a Calderón hasta el punto de confundirse con él» ${ }^{8}$. De estas comedias de género heroico continúa diciendo Mesonero Romanos que en ellas, dedicadas a representarse en los palacios reales, se sigue la corriente del gusto del público; que están repletas de delirios, metáforas, hipérboles y retruécanos, y que en todas ellas se descubre el ingenio y la delicada expresión de Solís ${ }^{9}$. Pero lo cierto es que Sánchez Regueira hace hincapié en que la

\footnotetext{
${ }^{3}$ Sánchez Regueira, Manuela, Introducción a Comedias de Antonio de Solís, 3-42 (Madrid: CSIC, 1984).

${ }^{4}$ Ibídem, 13.

${ }^{5}$ Ibídem, 6.

${ }^{6}$ Ibídem, 3.

${ }^{7}$ Ibídem, 13.

${ }^{8}$ Ibídem, 13.

${ }_{9}$ Ibídem, 15.
} 
distinta personalidad que caracteriza a Solís le describe como un autor que parece haber vivido en un periodo distinto, más evolucionado ${ }^{10}$. Y a esto debemos sumar la conclusión que Luis Arocena extrae de la fórmula fundamental de relaciones entre los personajes documentada en las obras de Solís por Eduardo Juliá Martínez: «Las obras de Solís son, pues, preferentemente feministas» ${ }^{11}$.

La comedia mitológica que aquí nos ocupa, Las Amazonas ${ }^{12}$, contiene los cinco elementos indispensables ${ }^{13}$ y que responden a la estructura base de relaciones entre personajes ${ }^{14}$ que el dramaturgo emplea en el grueso de sus obras: $\mathrm{A}=$ personaje principal de galán (Astolfo); $\mathrm{B}=$ personaje principal de dama (Miquilene); $\mathrm{C}=$ segundo galán (Polidoro); D = segunda dama (Menalife); $\mathrm{E}=$ pariente de una de las damas. Además, integra el común enredo provocado por la aparente relación entre A y D y, por otro lado, de B y C.

Sin perder de vista que la obra de Solís es un personal remanso de particularidades todavía inexplorado, es interesante considerar la opción que un estudio comparativo entre Astolfo y el personaje más célebre del teatro calderoniano ofrece como útil herramienta con la que realizar un acercamiento crítico para, a partir de él, continuar construyendo.

\section{ENTRE CONTRASTES E HIPOGRIFOS VIOLENTOS}

Con su distintiva naturaleza de personaje literario, el célebre protagonista de La vida es sueño ha trascendido los límites humanos para convertirse en símbolo, alegoría y arquetipo ${ }^{15}$. Como también señala Ruano de la Haza en el estudio introductorio a su edición crítica de la obra maestra calderoniana, La vida es sueño es una obra eminentemente teatral, por ello ha de ser leída y estudiada en dicha clave, sin olvidar su carácter «alegórico, religioso, filosófico, político y moral» ${ }^{16}$. Partiendo de las conclusiones de Ruano de la Haza en el mencionado estudio, no cabe duda de que Segismundo y Astolfo son seres completamente excepcionales que viven unos sucesos muy particulares en el marco de un subgénero dramático específico, la comedia, por lo que se hace necesario entender sus motivaciones y conductas en el contexto de las piezas dramáticas en las que intervienen. Por este motivo, es equívoco afirmar que representan principios generales sobre la existencia humana. Sin embargo, sí puede concebirse que comparten un semillero ideológico en cuanto al sentido de la existencia humana en base a sus respectivos dramas y a cada una de las acciones y planteamientos

10 Ibídem, 6.

${ }^{11}$ Juliá Martínez, Eduardo, Amor y obligación, comedia de Don Antonio de Solís y R. Edición, observaciones preliminares y ensayo bibliográfico. (Madrid: 1930). Citado Por Sánchez Regueira. Ibídem, 16.

12 Antonio de Solís estrenó Las Amazonas en Palacio el 7 de febrero de 1655, domingo de Carnestolendas, ante su Majestad Felipe IV. Serralta, Frédéric, "Nueva biografía de Antonio de Solís y Rivadeneyra", Criticón, 34, 1986, 88-92.

13 Amor, amistad, celos, boda y parentesco. Ibídem, 15.

${ }^{14}$ Representada por Julía Martínez. Citado por Sánchez Regueira. Ibídem,16.

${ }^{15}$ Ruano de la Haza, José María, Introducción a La vida es sueño de Pedro Calderón de la Barca, 7-68 (Madrid: Castalia, 2000), 36.

16 Ibídem, 35. 
epistemológicos que en ellos profesan, los cuales vienen dados por la singularidad de sus experiencias teatrales.

La singular riqueza de matices que los personajes literarios objeto de estudio presentan es indiscutible. La primera correspondencia entre ambos es la fatídica predestinación; en su destino estaba escrito que causarían la aniquilación de sus respectivos pueblos: «Segismundo sería / el hombre más atrevido, / el príncipe más crüel / y el monarca más impío; / por quien su reino vendría / a ser parcial y diviso, / escuela de las traiciones / y academia de los vicios» ${ }^{17}$. Igualmente, el oráculo vaticinó que si Astolfo llegaba a contemplar los rayos del sol, el Imperio de las Amazonas llegaría a su fin: «el tiempo / que goze de la hermosura / del Sol, se verà este Imperio / à los pies de la fortuna» ${ }^{18}$. Tirando de este lazo, vemos que ambos son personajes diseñados a la luz de un juego de contrastes. Ciriaco Morón, para explicar el primer verso de la obra calderoniana, en el estudio preliminar de su edición de La vida es sueño señala que:

El hipogrifo violento del primer verso no es simplemente salvaje; «violento» en Calderón tiene el sentido técnico de la escolástica: algo que contradice la naturaleza de una cosa; el hipogrifo es violento porque se compone de dos esencias distintas, cosa contradictoria. Rosaura es un ser violento porque, siendo mujer, viene vestida de hombre, tiene ánimo viril y, como se muestra en la escena décima del acto tercero (vv. 2690 y siguientes), actúa como mujer y como varón a la vez. Segismundo es un ser violento, es decir, compuesto de dos naturalezas: hombre por su nacimiento, y fiera porque no ha sido educado como hombre ni como príncipe. La grandeza del alma que le viene por ser hijo de rey, ha sido dejada a la pasión porque el príncipe no ha sido educado como tal: otra terrible contradicción ${ }^{19}$.

Con el personaje que configura Solís nos encontramos una serie de conexiones bastante significativas. Como hijo de Alexandro y Talestris, reina del Imperio de las Amazonas $^{20}$, la figura de Astolfo, un futuro rey, queda reducida a la miseria de un hombre que ha crecido privado del precioso don de la libertad ${ }^{21}$ y condenado a una sepultura en vida mientras recibe una educación extraña y nada propicia para su condición por parte de su maestro Indatirso. El lamento que emanan los primeros versos que nacen de la boca del hijo de Talestris son fruto de un profundo desconcierto. Desde el punto de vista de su condición humana, es totalmente

${ }^{17}$ Calderón de la Barca, Pedro, La vida es sueño. (Madrid: Castalia, 2000), 128, vv. 710-717.

18 Solís y Rivadeneyra, Antonio de, Comedias de Antonio de Solís, Tomo I. (Madrid: CSIC, 1984), 410.

${ }^{19}$ Morón Arroyo, Ciriaco, Introducción a La vida es sueño de Pedro Calderón de la Barca, 14-61 (Madrid: Cátedra, 1981), 19.

${ }^{20}$ En contra de sus propias leyes y siendo hijo varón del enemigo, fue dado a luz por su madre secretamente en la espesura de un bosque: «MIQUILENE. En el retiro de un bosque / (quiza ingeniosa busca) / pariò un infante». Solís, Comedias, 409.

${ }^{21} \mathrm{El}$ amor de madre de Talestris la empujó a fiar al anciano Indartiso su cuidado, educación y custodia; debía permanecer oculto en una gruta, ya que el oráculo predijo que, al igual que Segismundo, su hijo llevaría a su pueblo a la destrucción. 
comprensible lo que Astolfo siente; su vida ha transcurrido entre oscuridades ${ }^{22}$ terribles. En primer lugar, la de ser instruido sobre las maravillas que conforman el Universo y tener que imaginarlas, algo que, además, se agrava teniendo presente que lleva siendo esclavo de las paredes de su gruta durante toda su vida, siendo estas lo único que ha podido contemplar. Por otro lado, tenemos el desconocimiento, no solo del mundo ni del motivo que le ha condenado a una existencia tan miserable, sino también de sí mismo, de su procedencia, tal es así que incluso acierta a llamar padre a su maestro en determinadas ocasiones: «por las señas que me ha dado / mi padre, voy conociendo / las cosas» ${ }^{23}$. El anciano es la única persona con la que ha tenido contacto, por ello, a esto se suma la inevitable infelicidad provocada por la soledad.

Astolfo. Injusto padre mio,
que para hazer esclauo mi alvedrio
te vales de esta carcel de la tierra,
en cuyo seno lobrego se encierra,
por decreto del hado,
y muy vrgentemente infeliz, que sepultado
desde el instante mismo que he nacido,
solo conoce al Sol por el oído.
Ya me llama el valor, la gruta obscura,
que es mi vida mi propia sepultura,
por entre las junturas desta roca,
parece que desea abrir la boca ${ }^{24}$.

Estos alienados protagonistas, desconocedores de su verdadera identidad, inician sus primeras intervenciones a través del lamento. Pero, no es motivo suficiente para afirmar que se trata de una reflexión universal sobre el pecado original del hombre o sobre la existencia humana. Ruano de la Haza expone sobre La vida es sueño que:

Es ante todo la dramatización de la singular experiencia de un individuo que llega a ciertas conclusiones basadas en su extraordinaria experiencia teatral. La vida es sueño no es un tratado filosófico o un auto sacramental, cuyo objetivo sea reforzar un sistema teológico, filosófico y moral que personajes, dramaturgo y público poseen en común; es una comedia, que coloca a un personaje en una situación límite y

22 Uno de los motivos presentes en el texto.

23 Solís, Comedias, 388.

${ }^{24}$ Ibídem, 387. «Así, el Acto I empieza con el largo parlamento de Astolfo lamentando su situación de encierro; como nuevo Segismundo, oímos las quejas de un príncipe, encerrado en una cueva desde niño, que desconoce aún sus orígenes. Como indica la acotación escénica, "cae embuelto en poluo, vestido de pieles, y leuántase deslumbrado". Astolfo a su salida de la cueva, arrancando el peñasco que obstruía la entrada, da muestras de su asombro ante el espectáculo del mundo». Millán González, "Reinos de amazonas en la literatura española de la Edad Media y los Siglos de Oro: arquetipos, género y alteridad". (Tesis Doctoral, Universidad de Valencia, 2017), 414. http://roderic.uv.es/handle/10550/60811 (consultado el 28 de octubre de 2020). 
extraordinaria para observar cómo actúa y piensa en base a sus experiencias sobre el tablado $^{25}$.

Ahora bien, no debe perderse de vista la riqueza de alusiones inmersas en la obra: teológicas, mitológicas, ontológicas y políticas. Calderón y su amigo Solís coinciden en un mundo escolástico, «en el cual toda verdad de los paganos ha sido vista como robo de la verdad cristiana y, por consiguiente, como verdad originalmente cristiana» $^{26}$.

Las referencias al mundo griego no se limitan al platonismo. Rosaura se presenta como una amazona, sobre un hipogrifo, dispuesta a matar a un ingrato para restaurar su honor. Mujer y soldado, ella es tan contradictoria como el animal mitológico que la transportaba, y como la «fiera de los hombres» ${ }^{27}$ con que se encuentra. Segismundo es, por supuesto, un Prometeo encadenado, un titán dispuesto a luchar con los dioses. La primera escena de nuestra obra se sitúa, por tanto, en la atmósfera mítica de los héroes griegos ${ }^{28}$.

No parece casual que la comedia de Solís, protagonizada por un personaje cuyas circunstancias son tan excepcionales como las de Segismundo, tenga tantos nexos con La vida es sueño. Astolfo, del mismo modo, encaja con la visión que Morón emplea para referirse a Segismundo; se trata de otro Prometeo encadenado dispuesto, en su caso particular, a dar muerte a las Amazonas.

Asimismo, ambas obras presentan una clara rivalidad tripartita entre: la ley humana, la ley de Dios y la ley del cielo ${ }^{29}$. En La vida es sueño, el Rey Basilio toma unas decisiones equivocadas e incluso encaminadas al pecado, ya que no ejerce su obligación como padre: «Según la doctrina católica el matrimonio tiene un fin primario: tener hijos y educarlos». En lugar de eso, toma la tiránica decisión no solo de no educarle y de oprimir su libertad, sino de despojar al pueblo de su legítimo heredero fundamentándose en un saber difuso; el de las estrellas ${ }^{30}$. Así lo reclama el propio príncipe: «En lo que no es justa ley, / no ha de obedecer al Rey; / y su príncipe era yo»».

${ }^{25}$ Ruano de la Haza, Introducción, 44.

${ }^{26}$ Morón, Introducción, 15.

${ }^{27}$ Segismundo.

${ }^{28}$ Morón, Introducción, 16.

${ }^{29}$ «Calderón y los escolásticos admitían una influencia indirecta de las estrellas sobre la conducta humana. El hombre es una libertad fundida en tres coordenadas determinantes: cosmos, sociedad y lengua. Sabemos que existen las dos cosas: libertad e influencia. Pero, ni Calderón ni nosotros sabemos cómo y en qué grado se funden». Además, al final de la obra queda de perfecto manifiesto la supremacía de la prudencia frente a las estrellas. Morón, Introducción, 57.

30 «Además de ser indigno que un rey se dedique a la ciencia, la de las estrellas produce un saber puramente conjetural e inseguro. Si ese saber entra en conflicto con una obligación clara impuesta por el Evangelio y la Iglesia, la decisión tiene que caer en favor de la doctrina segura». Morón, Introducción, 58.

31 Calderón de la Barca, La vida es sueño, 161, vv. 1321-1323. 
Talestris comete el mismo error que Basilio; aunque su amor de madre la empujara a salvar la vida del infante, lo oculta en una gruta para impedir que su imperio se reduzca a la nada. El propio Astolfo, al conocer su verdadera identidad se muestra indignado por una hazaña tan bárbara como que su propia madre lo obligara a vivir de esa manera: «Astolfo. Si; pero negarme el cielo, / ya la luz del Sol, no ha sido / crueldad? INDATIRSO. Si; pero crueldad / religiosa del arbitrio / de tu madre / à quien la voz / del grande Apolo, predixo / à la ruyna de su Imperio» ${ }^{32}$. Incluso en su lamento inicial, cuando todavía no sabía nada sobre su procedencia, vemos que Astolfo califica el acto de condenarlo a una vida así como «piadosa crueldad» ${ }^{33}$. En Las Amazonas y en La vida es sueño se muestra, pues, a unos padres que, al no educar a sus hijos, acaban haciendo de ellos «hipogrifos violentos», es decir, monstruos impensables, puros entes de razón ${ }^{34}$.

\section{CONSTRUCCIÓN TEATRAL Y LIBERACIÓN DE LAS ALMAS CAUTIVAS}

«(Descúbrese Segismundo con una cadena y la lu₹, vestido de pieles $) »{ }^{35}$. Este príncipe se revela ante los ojos del espectador como un animal encadenado, este «dramático descubrimiento en el oscuro interior de la torre, con una luz que le ilumina débilmente y vestido de pieles, es altamente simbólico, pero también nos presenta en términos humanos la condición del personaje» ${ }^{36}$. Con ello, no deja de ser notoriamente sugerente la sensorialidad que emana el ruido producido por las cadenas que le mantienen preso en el momento previo a ser visto por Rosaura y Clarín. Este sonido provoca a ambos personajes la sensación de miedo y también la de misterio, que se ve incrementado por su esperada aparición: «(Suena ruido de cadenas). / CLARÍN. ¿Qué es lo que escucho, cielo? / ROSAURA. Inmóvil bulto soy de fuego y hielo ${ }^{37}$. / Clarín. Cadenita hay que suena, / ¡mátenme si no es galeote en pena! / Bien mi temor lo dice» ${ }^{38}$. Sabemos bien de la importancia de la música teatral pues, entre sus múltiples funciones, era empleada para subrayar la acción de la comedia y para anunciar las entradas y salidas de personajes importantes ${ }^{39}:$ «(Tocan, y sale el Rey Basilio, viejo, y acompañamiento $){ }^{40}$. Además, Ciriaco Morón subraya lo esencial que es la musicalidad en el Teatro del Siglo de Oro, especialmente en Calderón, puesto que «su auditorio en muchos casos no percibía contenido alguno del verso, más el sonido» ${ }^{41}$. En este caso, el sonido de la cadena está

32 Solís, Comedias, 429.

${ }^{33}$ Ibídem, 388.

34 Morón, Introducción, 58.

35 Calderón de la Barca, La vida es sueño, 91.

${ }^{36}$ Ruano de la Haza, José María. La puesta en escena en los teatros comerciales del Siglo de Oro. (Madrid: Castalia, 2000), 36.

${ }^{37}$ Calderón de la Barca, La vida es sueño, 89, vv. 73-77.

38 Ibídem, 89, vv. 73-77.

${ }^{39}$ Ruano de la Haza, La puesta en escena, 116.

40 Calderón de la Barca, La vida es sueño, 120.

41 Morón, Introducción, 48. 
anunciando no solo la entrada del desafortunado protagonista, sino que describe de antemano uno de sus rasgos elementales; el de ser un prisionero.

La primera aparición de Astolfo en Las Amazonas es, también, cuanto menos significativa: «(Arrancase un peñasco, que estarà fixo en la frente del teatro y con èl cae embuelto en polvo, vestido de pieles, y leuantase deslumbrado $\left.{ }^{42}\right){ }^{43}$. Esta caída junto al peñasco y el hecho de acabar repleto de polvo es bastante simbólico. Es el hombre primitivo por excelencia en el eslabón intelectual y social más bajo. No cabe duda de que son dos primeras apariciones muy reveladoras por otro motivo: su característico vestuario. Bien sabemos que este desempeña un papel crucial en la puesta en escena y en el desarrollo de la acción dramática de toda comedia en tanto que porta signos que facilitan la comprensión de la pieza ${ }^{44}$. Como apunta Ruano de la Haza:

Además de informar sobre la condición del personaje, la indumentaria podía servir para situar el lugar de la acción, el tiempo en que se desarrollaba y otros detalles similares; es decir, para transmitir al público información que, aunque pudiera hacerse por medio del diálogo, dramática y visualmente surtía más efecto a través de la indumentaria $a^{45}$.

Resulta evidente que no se trata de una entrada ni atuendo decorosos con la condición de dos personajes de ilustre linaje como Astolfo y Segismundo. Por ello, la indumentaria funciona como toda una simbología, pues la suma de la imagen interna y externa ${ }^{46}$ de los dos comienza a configurarse a partir de este momento y, con ello, se va a establecer un contraste bastante más marcado con respecto al antes y después de su cautiverio. Segismundo utiliza tres vestuarios diferentes en cada una de las jornadas: pieles durante la primera, traje cortesano en la segunda y pieles con un peto de soldado en la tercera ${ }^{47}$. Astolfo, en la jornada primera pieles, luego laurel ${ }^{48}$, espada, y bastón ${ }^{49}$. En este punto resulta apropiado tener en cuenta las conclusiones de Ruano de la Haza

42 Deslumbrado también por una luz metafórica: queda deslumbrado como hombre que mira de frente por primera vez a un nuevo y complejo mundo.

43 Solís, Comedias, 387.

${ }^{44}$ Ruano de la Haza, La puesta en escena, 73.

45 Ibídem, 90-91.

${ }^{46}$ Son salvajes porque sus almas lo son. Es interesante apreciar que la razón es la que realmente está «vestida de pieles».

47 Ruano de la Haza, Introducción, 73.

${ }^{48}$ El laurel también es mencionado en La vida es sueño. Por Clotaldo: «Si has estado / retirado y escondido, / por obedecer ha sido / a la inclemencia del hado, / que mil tragedias consiente / a este imperio cuando en él / el soberano laurel / corone tu augusta frente». Calderón de la Barca, La vida es sueño, 159, vv. 1276-1283. El laurel vuelve a reaparece en otras ocasiones, como en los versos de su propio padre, al final de la jornada tercera: «Hjio, que tan noble acción / otra vez en mis entrañas / te engendra, príncipe eres: / a ti el laurel y la palma / se te deben; tú venciste; / corónente tus hazañas». Ibídem, 267, vv. 3248-3253. Covarrubias dice del laurel que «auia de ser honrado y estimado el laurel, ciñendo no solo las sienes de los Poetas; pero tambié las sagradas cabeças dellos Emperadores en sus triunfos». Covarrubias Horozco, Sebastián de, Tesoro de la lengua castellana o española (Madrid: Biblioteca Digital Hispánica, 1611), 516, http://bdh-rd.bne.es/viewer.vm?id=0000178994\&page=1 (consultado el 5 de septiembre de 2020).

49 «(Salen solados con laurel, espada, y baston y se lo van poniendo)». Solís, Comedias, 399. 
sobre las pieles de las que se servían los actores para disfrazarse y representar papeles de animales, especialmente el del león, animal cuya aparición en las acotaciones de comedias es bastante frecuente ${ }^{50}$. Si bien es cierto que el león es considerado el rey de la selva, es también el animal que más temor genera, su naturaleza hace de este el depredador más peligroso ${ }^{51}$. Partiendo de este conglomerado de elementos teatrales, Segismundo y Astolfo son configurados en base a la contradicción, como auténticos salvajes; son dos brutos vestidos de pieles y, de este modo, el espectador ya se hace una idea del tipo de carácter conductual al que van a responder estos personajes, como veremos con posterioridad en la conducta que tienen tras saborear por vez primera los labios de la libertad. A ambos, como Morón afirma para explicar la conducta teatral de Segismundo, a pesar de que haya estudiado artes liberales, les falta la educación como príncipes, es decir, las «virtudes del oficio» descritas por Gracián ${ }^{52}$.

Despojados de sus pieles ${ }^{53}$, veamos el comportamiento de los personajes, comenzando por la primera reacción de Astolfo al inicio de la jornada segunda de Las Amazonas:

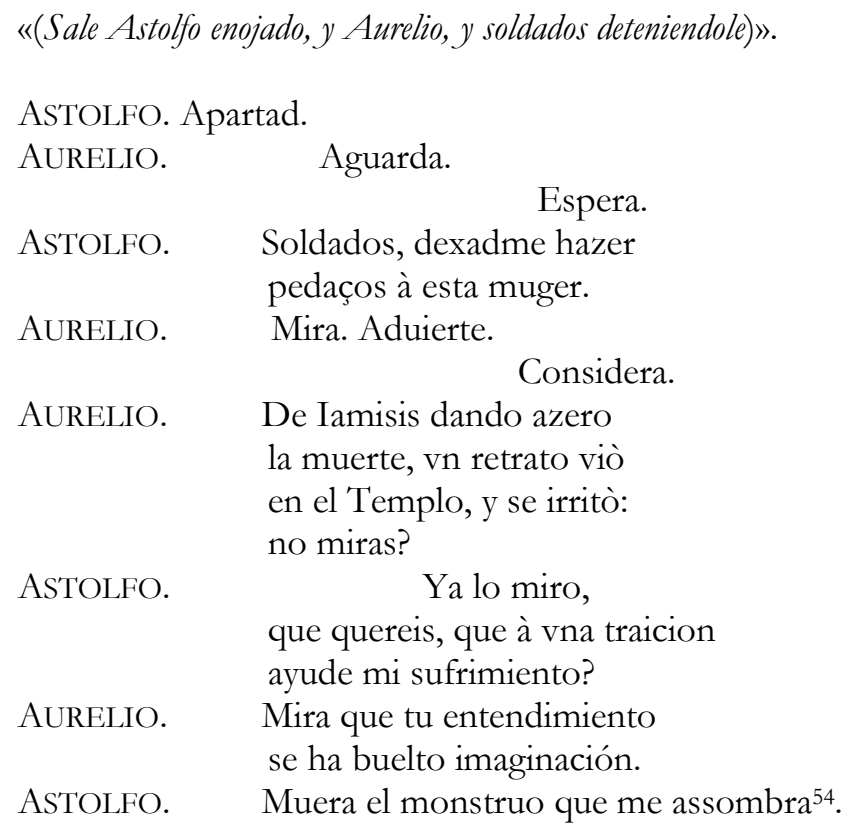

${ }^{50}$ Ibídem, 284-290.

${ }^{51}$ En la comedia No hay más saber que saberse salvar de Cristóbal Monroy, el demonio Luzbel aparece en escena y decide transformarse en un león para asustar Arsenio y Repilo, que se encuentran rezando de rodillas. En esta obra «el león representa la furia rapaz del demonio y su ansia de devorar a los humanos. Según el mismo Luzbel dice, San Pedro ya había llamado al demonio león (la referencia bíblica remite a I Pedro 5:8: vuestro adversario el diablo, como león rugiente, anda alrededor buscando a quién devorar)». Ruano de la Haza, La puesta en escena, 287-288.

52 Morón, Introducción, 26.

53 Solo en apariencia, es decir, en el plano físico.

${ }^{54}$ Solís, Comedias, 414. 
La conducta de Astolfo en el Templo al ver el retrato es cuanto menos primitiva. Su odio a la mujer, además de estar poco fundamentado, es irracional. La razón no tiene ningún tipo de cabida en él en tanto que nunca ha tenido ocasión de ver a una mujer, ni de comprobar si lo que de las Amazonas se cuenta se corresponde con la realidad. Debemos tener en cuenta que está emprendiendo el farragoso camino hacia la verdad, hacia el saber. Por lo tanto, lógicamente aún es incapaz de reprimir sus instintos. Es más, en los versos siguientes anuncia que le basta lo que ha leído sobre ellas para asesinarlas. Su animalidad se pone todavía más de relieve cuando sus emociones, en concreto, la ira, ciega su entendimiento, ya que ni siquiera es capaz de discernir entre un retrato y una mujer real porque nunca ha visto ninguna. En este Astolfo reluce la visceralidad con la que Segismundo inicia una sucesión de primitivas acciones en palacio. Primero amenaza a Clotaldo con darle la muerte por traidor: «SEGISMUNDO. Traidor fuiste con la ley, / lisonjero con el Rey, / y crüel conmigo fuiste; / y así el Rey, la ley y yo, / entre desdichas tan fieras, / te condenan a que mueras / a mis manos $»^{55}$. Luego, arroja a un criado por la ventana: «SEGISMUNDO. También oíste decir / que, por un balcón, a quien, / me canse, sabré arrojar. / [CRIADO] 2. Con los hombres como yo / no puede hacerse eso. / SEGISMUNDO. ¿No? / Por Dios, que lo he de probar. (...) SEgismundo. Cayó del balcón al mar. / ¡Vive Dios que pudo ser!! ${ }^{56}$. Todo ello, con el fin último de justificar sus acciones por su doble naturaleza de príncipe y fiera. En resumidas cuentas, de las fieras ha aprendido «que los reyes entre ellas son temidos y respetados» ${ }^{57}$. Esto mismo se aprecia en su instinto de poseer a las dos hembras que se encuentra, Rosaura y Estrella. Asimismo, Astolfo, siguiendo los pasos de Segismundo en su primer encuentro con Rosaura, a la que quiere darle la muerte por haber escuchado sus «flaquezas», se dirige firmemente convencido a dar muerte a lo que él cree que es una mujer mientras Aurelio trata de detenerle.

Aurelio. Dexa à tu ingenio cruel, sin que del dudar se ofenda, que si no es saber es senda el dudar para el saber.

$\mathrm{Y}$ assi viene à ser el dudar, del saber tan cierta seña, que pede dezir que enseña el que sabe preguntar.

ASTOLFO. Pues ya que puedo vencer esta ignorancia en que estoy, sabe Aurelio que hasta oy, no he visto alguna muger. Y como en los libros leo, que es tan cruel, y irritada, nunca ha perdonado nada

\footnotetext{
55 Calderón de la Barca, La vida es sueño, 160, vv. 1305-1312.

${ }^{56}$ Ibídem, 168-169, vv. 1422-1431.

${ }^{57}$ Ruano de la Haza, Introducción, 41.
} 
de lo atroz, ni de lo feo ${ }^{58}$.

Estos versos de Aurelio suponen un mayéutico manifiesto sobre el método para llegar al saber: Astolfo ha de aprender a preguntar para así aprender y llegar al saber. La prudencia humana es la que debe evitar ser embaucada por las falsas apariencias, pero Astolfo no ha sido educado ni como príncipe ni como ser humano, sino como fiera. De hecho, la falta de control sobre sus emociones ya es palpable cuando el protagonista se encuentra con Lucindo en la jornada inicial, la primera pasión que lo domina a raíz de la insuficiente información que el gracioso le proporciona sobre la historia de las Amazonas y el origen de su imperio es la ira: «Astolfo. De ira tiemblo, / ven acà, suele la ira / produzir essos efetos?» ${ }^{59}$. Asimismo, Aurelio determina explicar a nuestro inexperto príncipe que debe reprimir sus impulsos y pasiones ${ }^{60}$, esto es, ha de ser prudente y para poder serlo debe tener fuerza de voluntad:

\begin{tabular}{lc} 
ASTOLFO. & Y quien podrà contra mi irritarle? \\
AURELIO. & Tu alvedrio. \\
ASTOLFO. & \multicolumn{2}{c}{ Esse no es libre? } \\
AURELIO. & Es verdad. \\
ASTOLFO. & \multicolumn{2}{c}{ Pues como su daño. } \\
AURELIO. & Pues no es èl quien se rige. \\
ASTOLFO. & Pues quien es? \\
AURELIO. & \multicolumn{1}{c}{ La voluntad elige? } \\
ASTOLFO. & Y el entendimiento? \\
AURELIO. & \multicolumn{2}{c}{ Errado } \\
ASTOLFO. & se dexa della vencer. \\
AURELIO. & Si, pero meno mas poder?
\end{tabular}

Este planteamiento recuerda al momento en que Clotaldo le sugiere a Astolfo que no está de más hacer el bien incluso en sueños: «Como habíamos hablado / de aquella águila, dormido, / tu sueño imperios han sido; / mas en tus sueños fuera bien / entonces honrar a quien / te crió en tantos empeños, / Segismundo, que aun en sueños / no se pierde el hacer bien» ${ }^{62}$. En estas enseñanzas se respira el influjo de la tradición clásica sobre la virtud, «hábito selectivo que consiste en un término medio relativo a nosotros, determinado por la razón y por la cual decidiría el hombre

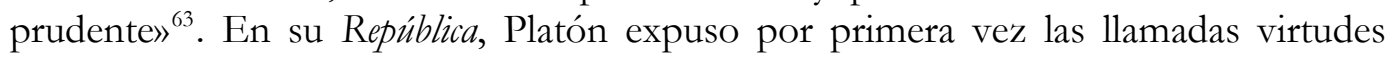

58 Solís, Comedias, 417.

${ }^{59}$ Ibídem, 396.

60 «En ese desborde de pasión, controlado siempre por la razón escolástica como por una camisa de fuerza, consiste probablemente la esencia del barroco». Hatzfeld, Helmut, «Lo que es barroco en Calderón», en Hacia Calderón. Segundo Coloquio Anglogermano, 35-49. Citado por Morón, Introducción, 52.

${ }^{61}$ Solís, Comedias, 417-418.

62 Calderón de la Barca, La vida es sueño, 209, vv. 2140-2147.

63 Aristóteles, Ética a Nicómaco (Madrid: Fareso, 1989), 26. 
cardinales, que pasaron a consolidarse como base de la moral humana en el pensamiento filosófico occidental. Son cuatro: justicia, templanza, fortaleza y prudencia, aunque en la obra del filósofo aparecen mencionadas por primera vez en el siguiente orden y con las siguientes denominaciones: justicia, templanza, valor y sabiduría ${ }^{64}$.

Desde el inicio de los tiempos, Dios ha dado al hombre el atributo esencial del libre albedrío ${ }^{65}$ para erigir su destino y a sí mismo escogiendo entre todas las posibilidades que le brinda el universo la mejor de ellas, algo que, además, le obliga a ser consciente de la responsabilidad moral que tiene. Y, el hombre prudente no es otro que aquel que hace un uso adecuado de su libertad para encaminar la voluntad hacia la acción recta moralmente, es decir, hacia el bien. Por lo tanto, si se llevan a cabo buenas acciones desde la libertad, se puede salir victorioso frente a la predestinación. Pero, ¿cómo pueden aprender a poner esto en práctica dos hombres que han vivido solos en un agujero oscuro la inmensa mayoría de sus días? Sabemos que, en el caso de Segismundo, su propia experiencia es lo que le mueve a hacer el bien. El Segismundo de la tercera jornada pone en práctica lo que ha aprendido empíricamente; es consciente de que si obra bien, es probable que el «sueño» sea más duradero ${ }^{66}$ y así lo demuestra en escenas posteriores. Cuando Clotaldo se mantiene fiel a su rey en lugar de luchar junto a Segismundo contra su padre, esta vez el príncipe es capaz de dominar su ira y lo deja marchar para reunirse con él. Reprime nuevamente sus pasiones cuando renuncia a Rosaura ${ }^{67}$, conquista su honor y finalmente la hace esposa de su primo Astolfo, príncipe de Moscovia. De igual forma, el Astolfo de la tercera jornada pone en práctica los conocimientos que ha adquirido de las experiencias vividas en la jornada anterior. Es consciente de que las pasiones desatadas por el amor ${ }^{68}$ no controladas

${ }^{64}$ Tratadas en el libro IV de dicha obra. Platón, La República (Barcelona: Altaya, 1993), 161-212.

${ }^{65}$ Esto, según los argumentos metafísicos cristianos, procedentes de la filosofía agustiniana ( $D e$ libero arbitrio), que resaltan el valor de la libertad del alma humana como privilegio de su especial semejanza con Dios. Sin embargo, su radical limitación y la influencia del pecado (las inclinaciones voluptuosas) hacen precisa una intervención divina en aras de propiciar que la libre elección se haga efectiva en la medida en que se elija el bien. A esta intervención que hace posible la libertad humana como facultad de redención se le denominó la «gracia».

Pero, la existencia -O no- del libre albedrío ha sido tema central a lo largo de la historia de la filosofía y la ciencia; y las teorías deterministas, tanto religiosas (Calvino, Lutero, el Islam), como lógicas, metafísicas, físicas o psicológicas (sostenidas por pensadores como Spinoza, Laplace, Hume, Schopenhauer) niegan el libre albedrío al creer al hombre movido por la voluntad divina, por un lado, y por leyes físicas y psicológicas, por otro. Para Freud, el motivo que hace actuar al ser humano son las condiciones inconscientes de la realización de su deseo, y la libertad consistirá en la aceptación consciente de las mismas.

${ }^{66}$ Ruano de la Haza, Introducción, 45.

${ }^{67}$ «No dice que va a luchar por conquistar la honra de Rosaura, sino que huir él de la dama en este momento es la mejor forma de ampararla». Morón, Introducción, 31.

${ }^{68}$ Lo que el ínclito Ruiz Ramón denominaba uno de los tres «círculos concéntricos» de la obra: «la vida es sueño» o el de la realidad-ficción, junto con el vencerse a sí mismo y el de libertad-destino. Ruiz Ramón, Francisco, Historia del teatro español (Madrid: Cátedra, 2011).

A su vez, el amor actúa como impulso que ennoblece al hombre. Del mismo modo, Ciriaco Morón nos dice que «el amor, la memoria y la salida de la caverna son a un primer nivel tres instancias de 
pueden conducir a la destrucción personal y ajena; a la brutalidad, a la tiranía y a la guerra.

\section{CONFUSIÓN Y DESENGAÑO: ESTADO PREVIO Y OPUESTO AL BIEN Y A LA VERDAD}

Partiendo del hecho de que Segismundo y Astolfo son hombres que «conocen el mundo tan solo por el oído», cabe retomar la cuestión de la oscuridad, que se vincula con el estado de confusión en el que viven los personajes. Con oscuridad, nos referimos al desconocimiento de la «verdad», algo que los convierte en esclavos de la duda entre lo real y lo imaginario y que apunta en la dirección de los motivos puramente barrocos: la apariencia, el desengaño, la teatralidad, las máscaras, lo ilusorio. Sabemos que la peculiar experiencia de Segismundo en palacio le impide diferenciar la realidad de lo soñado, el móvil que le lleva a esta situación es el propio «sueño» que le hacen creer que ha tenido. Su convicción acaba por ser que «la vida se vive en diferentes planos de realidad, uno de los cuales se denomina sueño» ${ }^{69}$. A raíz del castigo que ha supuesto para él despertar de ese sueño, se esfuerza por mejorar su conducta para así evitar de nuevo el cruel desengaño y la fugacidad de su dicha.

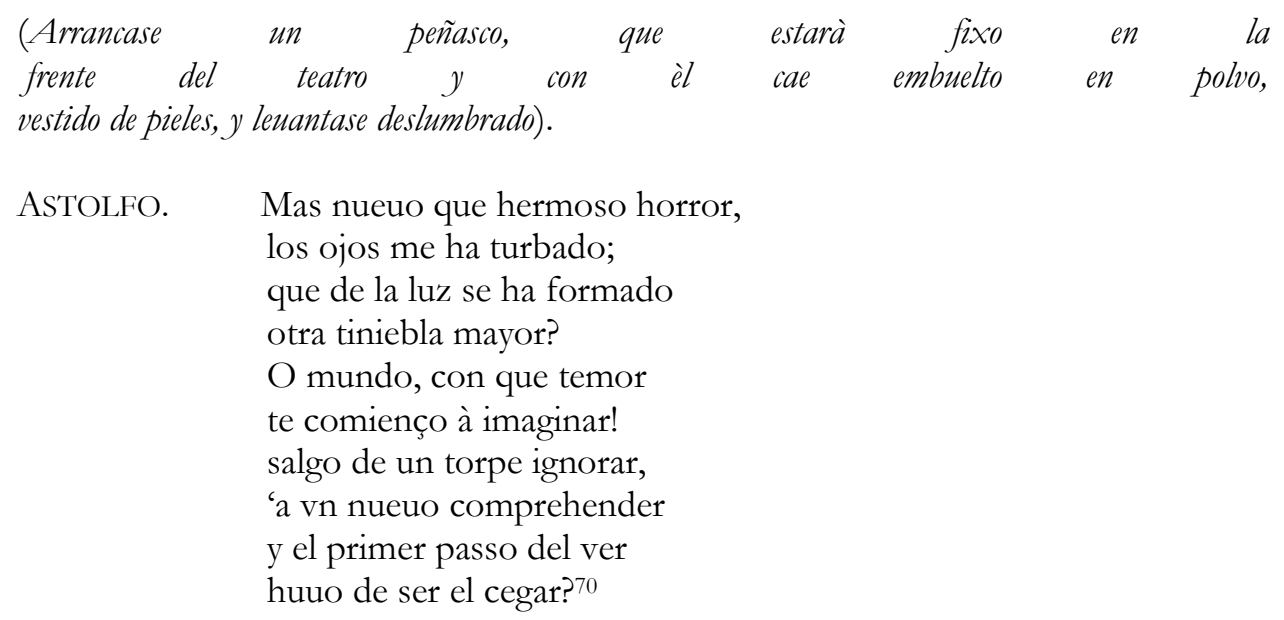

Del mismo modo, como toda la vida de Astolfo ha transcurrido en el interior de una lúgubre cueva, su existencia que se ha basado en otro desengaño; el de la imaginación. Al desprenderse parte de la pared de la gruta, consigue ver un atisbo de lo que es un nuevo mundo para él, un mundo con el que, de alguna forma, también ha tenido que soñar. El protagonista de Solís expresa el temor que este «hermoso horror» le causa, a diferencia de la admiración de Segismundo: «SEGISMUNDO. ¡Válgame el cielo, qué veo! / ¡Válgame el cielo, qué miro! / ¡Con qué poco espanto lo admiro! /

platonismo» en La vida es sueño. La memoria es la experiencia de verdad humana porque ese recuerdo del sentimiento amoroso le asegura a Segismundo que no estaba soñando. Ibídem, 53.

${ }^{69}$ Ruano de la Haza, Introducción, 43.

${ }^{70}$ Solís, Comedias, 387-388. 
¡Con mucha duda lo creo!» ${ }^{71}$. Asimismo, Astolfo admite la diferencia existente entre el mundo que se había dedicado a construir en su imaginación a partir de sus lecturas y el que se ha encontrado ante sus ojos, es decir, el que está percibiendo mediante los sentidos:

AstolFo.
Estraña maquina es esta
que descubro, aunque leyendo
los libro, aunque estudiando
las facultades que debo
à la piedosa crueldad
de mi padre, ò mi maestro,
he imaginado las cosas
que forjan el Vniverso.
No me las supo explicar
de la forma que las veo,
debe de ser, porque siempre
lo material del sugeto
lo comprehende el sentido,
mejor que el entendimiento

No cabe duda de la evidente huella que el platonismo ha dejado en los versos. Como en la alegoría del filósofo, la única verdad que Astolfo conoce, como habitante del espacio cavernoso que es la gruta, es la de las cosas que ha trazado en su imaginación; son las sombras proyectadas, en concreto, por los libros. Al verse deslumbrado por la luz de una nueva realidad, mucho más profunda y compleja, surge en él una evidente sensación de incomodidad. Posteriormente, del temor y el asombro pasa a la decepción. En lugar de mostrar admiración ante tal descubrimiento se lamenta de que la realidad que se ha encontrado es menor que aquella que la imaginación dibujó en su mente, un terrible desengaño. Esto establece un vínculo con la ardua labor de desprenderse del mundo antes conocido, fundamentado por las apariencias sensibles, para encaminarse al nuevo y dificultoso entendimiento, de ahí que exprese en sus versos iniciales que el paso previo del ver es el cegar.

ASTOLFO. No sè que espíritu grande me acompaña, aunque nueuo para mí, quanto descubro todo me parece menos, que aquello que imaginè. Solo esse açul pauimento de los Dioses, y essa luz, y el Autor de sus reflexos, son mas que supo fingir en sus simulacros ciegos

${ }^{71}$ Calderón de la Barca, La vida es sueño, 156, vv. 1224-1227.

72 Solís, Comedias, 388. 
mi idea; pero que mucho, esta tierra, y aquel cielo, y aquì es oro imaginado lo que posseìdo es hierro. Y allí siempre halla la mano, mas que prometiò el deseo: que avrà, pues, que avrà que pueda con este conocimiento admirarme?73

El inexperto Astolfo recién liberado de su caverna es incapaz de distinguir qué es inteligible, real, y qué es producto de sus sentidos, es decir, imaginario. Este estado de confusión reluce en todo su esplendor al inicio de la segunda jornada de la pieza, momento en que ve la imagen ${ }^{74}$ de una mujer en el Templo y la confunde con una mujer de verdad, ya que nunca ha visto ninguna:

«(Sale Astolfo enojado, y Aurelio, y soldados deteniendole $) »$.

Astolfo. Apartad.

AURELIO. Aguarda.

ASTOLFO. Soldados, dexadme hazer

Espera.

pedaços à esta muger.

Aurelio. Mira. Aduierte.

AURELIO. De Iamisis dando azero

la muerte, vn retrato viò

en el Templo, y se irritò:

no miras?

ASTOLFO. Ya lo miro,

que quereis, que à vna traicion

ayude mi sufrimiento?

Aurelio. Mira que tu entendimiento

se ha buelto imaginación.

ASTOLFO. Muera el monstruo que me assombra ${ }^{75}$.

Otro engaño producto de las apariencias vuelve a darse en el palacio de las Amazonas. El enredo producido por el encuentro secreto entre Polidoro y Menalife en la habitación de Miquiline le lleva a imaginar que es ella la que oculta a Polidoro como amante suyo, lo que le conduce a una terrible confusión que desata en él las pasiones que lo acaban moviendo al campo de batalla: la ira y los celos. Con ello, en ambas comedias parece factible la equiparación del plano del sueño, de lo ilusorio, de lo aparente, con el plano de lo sensible que, a su vez, es opuesto al plano inteligible, reinado por la razón.

\footnotetext{
73 Ibídem, 389.

${ }^{74}$ Sombra y apariencia .

75 Solís, Comedias, 414.
} 


\section{DEL ESPACIO CAVERNOSO A LA LUZ DE PALACIO: ESPACIOS DRAMÁTICOS Y METAFÓRICOS}

La clara oposición entre los dos escenarios donde se desarrollan las acciones de ambos dramas es indiscutible. Tanto en Las Amaronas como en La vida es sueño se produce una transición que Ciriaco Morón denominaría «del monte a palacio» ${ }^{76}$. El diseño espacial de la acción dramática para representar ideas antagónicas es crucial para reflejar la evolución del carácter de los protagonistas. La gruta y la torre frente a palacio son espacios dramáticos pensados para simbología, pues estos dos tipos de espacios «conforman dos presencias espaciales genéricas que se intuyen, se presienten, con mayor o menor intensidad, como realidades que trascienden el ámbito escénico y escenográfico. Se trata de localizaciones que se plantean en forma tematizada, es decir, en abstracto, y que se figurativizarán por medio de varios espacios presentess ${ }^{77}$. En el inicio de las piezas teatrales los personajes son ubicados en espacios exteriores rústicos como reflejo de su primitiva naturaleza interior. El palaciego, por su parte, puede concebirse como entorno de la razón, del ideal político, de la luz, del pensamiento elevado, de la formalidad conductual, de la protección del honor, de la sujeción de las pasiones humanas y de la supremacía del pensamiento racional sobre los placeres sensibles. Por lo tanto, es un espacio dramático que responde al mundo «inteligible», pues no hay que mirar más allá del obligado cumplimiento de las normas morales que este requiere. En La vida es sueño «el monte sería el escenario de la pasión y el palacio el de la civilización, la razón y el orden ${ }^{78}$. Estos dos tipos de espacios dramáticos son alternados de igual manera en Las Amazonas. En el marco de la comedia aurisecular española es frecuente la contraposición entre localizaciones urbanas y rústicas: «urbs» versus «rus». No se trata simplemente de una contraposición entre ciudad y naturaleza, sino de un interior y un exterior metafóricos. Tanto la gruta como la torre están ubicados en un ámbito rural, exterior, donde la relajación del comportamiento se ve favorecida. «El campo es un lugar alejado físicamente del entorno urbano, pero también, desde el punto de vista moral, de sus códigos de conducta» ${ }^{79}$ (v. 27). Por esta razón, son escenarios que apuntan en dirección de lo tangible, de lo sensorial, en los que entran en juego elementos como la percepción, la anulación de la razón por los sentidos, la confusión del entendimiento y la proyección de las emociones y sentimientos. Este entorno, «cuando no es terreno de Amor, entonces la admiración que genera el arte y lo bello ante los ojos del hombre, se revela a través de la intensa

${ }^{76}$ Morón, Introducción, 25.

77 Sáez Raposo, Francisco. Introducción a Amar por razón de Estado de Tirso de Molina, 13-67 (Nueva York / Madrid: Instituto de Estudios Auriseculares / Instituto de Estudios Tirsianos, 2019), 23, https://hld.handle.net/10171/56818, (consultado el 27 de agosto de 2020).

${ }^{78}$ Morón, Introducción, 25.

${ }^{79}$ Sáez Raposo, Introducción, 27. 
reflexión de búsqueda de sí mismo. Viéndose en un espacio solitario, el hombre se introduce en el camino sinuoso y laberíntico de su ser» ${ }^{80}$.

En términos filosófico-simbólicos, gruta y torre son cárceles, espacios de tinieblas, sueños, imaginación e ignorancia, de los cuales los personajes se liberan para iniciar un vertical proceso de ascensión hacia el bien y la verdad. En este viaje en dirección a lo inteligible queda atrás la materia sensible, así como el desconocimiento del mundo y de sí mismos. Al final del escarpado recorrido encontrarán la luz; la amplia iluminación que aguarda en palacio, luz de la razón y del triunfo de la virtud.

\section{HUMANIZACIÓN DE LA FIERA QUE ES EL HOMBRE}

«La vida es sueño es la dramatización de ese paso de la violencia a la prudencia, entendidos ambos términos en sentido escolástico» ${ }^{81}$. Lo que puede apreciarse a partir del análisis de rasgos específicos de las obras que aquí nos ocupan es que todo hombre y, por lo tanto, todo príncipe vive una lucha constante entre la pasión y la prudencia ${ }^{82}$. Esta última ha de sobreponerse a la primera ${ }^{83}$. Además, para gobernar no es suficiente tener un linaje noble si no se sabe dirigir el comportamiento hacia el buen proceder, con lo que también se vislumbra el ideal monárquico del periodo en que ambas obras se circunscriben. De hecho, el papel del gobernante ha de desempeñar una labor inmaculada como referente ante su patria. Por el contrario, los salvajes príncipes eran incapaces de gobernar. Las acciones con las que transcurre la tercera jornada de La vida es sueño, comenta Ruano de la Haza que «marcan para el público de la época la realización de obrar bien y la incorporación definitiva del alienado, diferente y marginado Segismundo al modo de pensar y al sistema filosófico, político, moral y ético de su época» ${ }^{84}$.

Tomando la trayectoria del príncipe como una perspectiva legítima, aunque limitada, podemos decir que la humanización no es brusca, sino una constante lucha entre pasión y razón, naturaleza y arte, que comienza con el dominio de la primera y termina con el triunfo de la segunda. La vida es sueño es, en este sentido, un «regimiento de príncipes» ${ }^{85}$.

Las Amazonas parece apuntar en una dirección relativamente semejante. El cruel inicio que marca la esencia de los personajes subraya la relevancia que la buena educación tiene como freno y fuerza templadora de la animalidad. Cuando Segismundo

${ }^{80}$ Alvarado Teodorika, Tatiana, "El jardín en el teatro aurisecular. Las comedias mitológicas de Calderón", Actas del XVI Congreso de la Asociación Internacional de Hispanistas (AIH): Nuevos caminos del hispanismo, vol. 2 (2010), 8-9, https://cvc.cervantes.es/literatura/aih/pdf/16/aih_16_2_049.pdf (consultado el 23 de agosto de 2020).

81 Morón, Introducción, 20.

82 «La pasión de los personajes está siempre controlada por la razón y hasta por el racionalismo de su creador, Calderón de la Barca». Ibídem, 52.

83 Ibídem, 59.

${ }^{84}$ Ruano de la Haza, Introducción, 47-48.

85 Morón, Introducción, 32. 
y Astolfo abandonan sus respectivas prisiones y se inician en la educación sentimental y moral dada por sus experiencias con el resto de personajes se desenmascaran dos cuestiones: por un lado, el carácter monstruoso del ser humano cuando vive en soledad y sin la instrucción necesaria ${ }^{86} \mathrm{y}$, por el otro, que una libertad al servicio de la prudencia y de la voluntad posibilitan trazar un camino al margen del destino escrito.

La vida es sueño y Las Amazonas son piezas teatrales de las que se desprenden imágenes opuestas muy poderosas. El verso inicial de la primera de ellas, «hipogrifo violento» ${ }^{87}$, que sugiere la imagen de un caballo desbocado, es indiscutiblemente antónimo al que Rosaura utiliza en la última escena en referencia al príncipe: «QQué discreto y qué prudente! $\rangle^{88}$. En la primera jornada de Las Amazonas tenemos a un Astolfo furioso y vengativo cuya mente está nublada por el deseo de asesinar a las mujeres y, llegando el final de la tercera jornada, este se postra completamente rendido de amor por una de ellas: «Para solo amarte quiero / viuir, si à mi muerte aspiras, / dexate estar en el alma, / y lleuate allà la vida» ${ }^{89}$.

Solo en su monólogo último está Segismundo verdaderamente humanizado. A la humanización platónica por la belleza y a la senequista por la brevedad de la vida, se suma la cristiana, aunque muy débilmente. Nuestra obra es indudablemente cristiana, pero de un cristianismo escolástico que está más cerca de Aristóteles y Séneca que de la Biblia ${ }^{90}$.

Lo cierto es que la humanización en ambos personajes se da de forma diferente. A lo largo del segundo acto las acciones de Segismundo están influenciadas por los narcóticos que le han suministrado, pero en medio de su constante actividad nerviosa se vislumbra al ser pensante, lógico y racional que es capaz de argumentar brillantemente con Basilio ${ }^{91}$, aunque no es hasta después de la batalla contra este que se puede hablar del nuevo Segismundo. No negaremos la curiosidad intelectual que Astolfo despliega en sus planteamientos y reflexiones. Pero, en sus versos difícilmente puede decirse que se aprecie un dominio gradual de sus emociones. El hijo de Talestris inicia su proceso de conversión de animal a ser racional en el momento en que hace uso de la gruta para introducirse en el palacio de las Amazonas. Partiendo de las premisas anteriormente expuestas, estamos hablando no solo de un cambio de espacio dramático, sino también metafórico. Es evidente que no es el mismo hombre que habitaba la gruta, pero hasta que Lucindo no le esclarece que son Menalife y Polidoro los verdaderos amantes que se vieron en secreto en los aposentos de Miquilene, no hay un cambio eminente en la conducta y forma de pensar del personaje:

86 Aunque en el caso de Astolfo sí se comenta que tenía muchas lecturas hechas y las lecciones de un preceptor; de lo que carecía es de la experiencia propia, sensitiva, de la realidad; algo que solo se puede aprender por uno mismo, que no se puede enseñar.

${ }^{87}$ Calderón de la Barca, La vida es sueño, 81, v. 1.

88 Ibídem, 270, v. 3304.

${ }^{89}$ Solís, Comedias, 459.

${ }^{90}$ Morón, Introducción, 32.

${ }^{91}$ Ruano de la Haza, Introducción, 48. 
Astolfo. Que Polidoro es amante de Menalife, y que èl fue el que yo anoche encontré (albricias amor constante), en el quarto de la hermosa

LUCINDO. Assi es verdad. Miquilene?

Astolfo. Pues soldados, escuchad, ya està menos belicosa el alma (venciste amor) triunfaste mis rezelos, y con quitarme los zelos, me has desarmado el valor ${ }^{92}$.

Hasta este preciso momento no interviene Astolfo como ser totalmente pensante y racional. El descubrimiento de esta nueva información desemboca en un discurso inundado de sensatez con el que el protagonista pretende aplacar a los soldados. "La muger no naciò sujeta al hombre / por natural decreto? el propio nombre / no es simbolo comun de la flaqueza? / Lo propio que condicion su fortaleza? / pues porquè ha de comprehenderse como hazaña / el salir oy con ellas en campaña?» ${ }^{93}$. Astolfo manifiesta que no puede considerarse una hazaña la empresa de luchar contra las Amazonas, sino todo lo contrario, puesto que en términos teológicos esta nace sujeta al hombre, por ser menos fuerte por naturaleza, esto es, llena de flaquezas. Al igual que en La vida es sueño Segismundo cumple con su deber de salvaguardar el honor de Rosaura, en Las Amazonas, Astolfo razona:

Yo doy lo que las vencimos, que vencemos, aquello mismo que amparar debemos? no es suyo nuestro ser? el mas ayrado no vltrajarà con mano impetuosa la imagen de su dama, ù de su esposa? Las mugeres, amigos, ya sabemos, que si, las maltratamos las perdemos ${ }^{94}$.

La prudencia no se encuentra simplemente en obrar bien, en no enfrentarse a las mujeres, sino en no dejarse dominar por los efectos y pasiones que estas despiertan en el hombre; por ello indica posteriormente a las tropas que deben mantener la templanza en el encuentro: «siendo assi, que su enojo, su osadia, / su impaciencia, su ardor, su demasia / podrà solo en el hombre mas tirano / el pecho» ${ }^{95}$. Esta templanza debe entenderse no solo como el control de la ira o de los celos sino también, claro está, del apetito sexual. Los hombres tienen la misión de ir en contra de sus deseos

\footnotetext{
92 Solís, Comedias, 453.

93 Ibídem, 455.

94 Ibídem, 455.

95 Ibídem, 455.
} 
nacidos del encanto femenino, es decir, de no dejarse embaucar sus sentidos por la presencia de las mujeres: su belleza física, su voz, su olor:

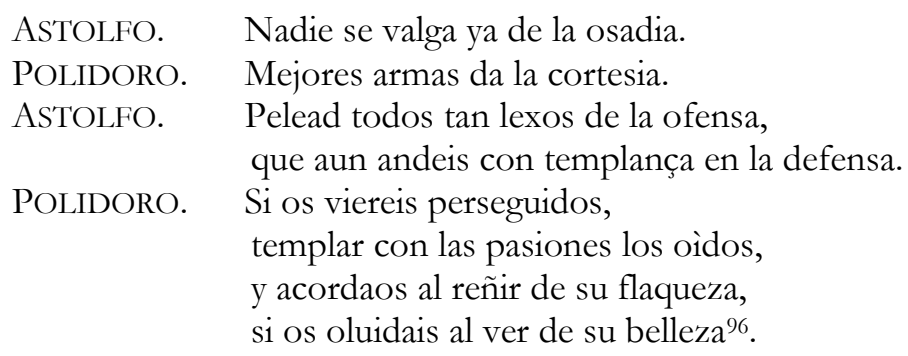

Una nueva señal de que la animalidad se ha apartado a un lado para dar paso a la intelectualidad en Segismundo se encuentra en los versos en los que anuncia la firme intención de encaminar sus acciones al bien: «acudamos a lo eterno / que es la fama vividora / donde ni duermen las dichas / ni las grandezas reposan ${ }^{97}$. Frente a la fugacidad de los placeres sensibles, cuya satisfacción no perdura ni causa efectos positivos ni en él ni en el resto de personajes, Segismundo aboga por perseguir la «fama vividora». La gloria eterna es aquello que nunca perece ni caduca, lo que verdaderamente trasciende y proporciona una dicha de carácter inmortal. Por lo tanto, hay una clara relación entre acción encaminada al bien y felicidad. De igual manera, esta elevada aspiración es perseguida por Astolfo, que manifiesta a lo largo de esta serie de intervenciones una sabiduría propia de un rey:
Astolfo. Que con esso soldados, lidiais como corteses, y esforçados.
POLIDORO. Se assegura el sucesso desta victoria.
AstOLFO. Se dobla al esplendor de otra gloria.
POLIDORO. Venceis con el afan de la batalla.
ASTOLFO. Y Y la fama obligais con no mancharla98.

Esta no es otra que la victoria que los personajes obtienen sobre sí mismos; su humanización. Han conseguido despojarse por completo de sus pieles, así como dar sentido a su existencia como seres racionales y sociales. Pasión contra razón es la violenta lucha a la que todo hombre y todo príncipe ha de enfrentarse y ambos han logrado sobreponerse a su salvaje naturaleza, es decir, ahora son capaces de dominar la brutalidad y los instintos inherentes en el alma humana. Esto demuestra que el destino puede ser vencido determinando correctamente la voluntad:

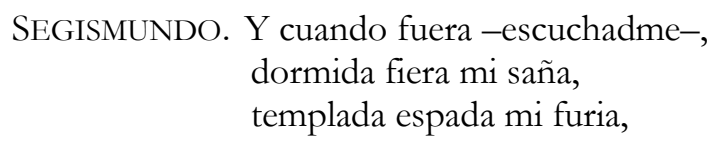

${ }^{96}$ Ibídem, 456.

${ }^{97}$ Calderón de la Barca, La vida es sueño, 253-254, vv. 2982-2985.

${ }^{98}$ Solís, Comedias, 456. 
mi rigor quieta bonanza,

la fortuna no se vence

con injusticia y venganza;

porque antes se incita más.

Y así, quien vencer aguarda

a su fortuna, ha de ser

con prudencia y con templanza ${ }^{99}$.

Lo que está de Dios se cumple pero a través de «causas segundas», es decir, de acciones segundas que pueden ser meritorias o culpables ${ }^{100}$. El propio Segismundo así lo recuerda en su último monólogo: «Sentencia del cielo fue. / Por más que quiso estorbarla / él, no pudo; y podré yo, / que soy menor en las canas, / en el valor y en la ciencia, / vencerla» ${ }^{101}$. En la comedia de Solís sí acaba por cumplirse el vaticinio del oráculo de Apolo, ya que concluye con el casamiento de Polidoro y Menalife y de Astolfo y Miquilene. La integración del hombre en una civilización fundada y compuesta en exclusiva por la figura femenina conduce al fin del Imperio de las Amazonas, pero no causa su destrucción ni derramamiento de sangre alguno.

En resumidas cuentas, tanto Segismundo como Astolfo al final se nos presentan como hombres opuestos a su barbarie inicial, en pleno dominio de sus emociones e inscritos en la ideología de su época y sociedad. Ambos representan la lucha del ser humano por dar sentido a su extraordinaria existencia, al igual que su socialización, o aceptación del código de conducta y sistema de creencias de su sociedad. Este anhelo y preocupación que manifiestan es algo común a todo ser humano, esto es precisamente lo que los convierte en un universal, dentro de sus singularidades como personajes dramáticos únicos e irrepetibles ${ }^{102}$.

${ }^{99}$ Calderón de la Barca, La vida es sueño, 265, vv. 3210-3219.

100 Morón, Introducción, 35.

${ }^{101}$ Calderón de la Barca, La vida es sueño, 266, vv. 3236-3241.

102 En esta línea, resulta de gran provecho aplicar a la condición de ambos personajes las estimaciones finales con las que Ruano de la Haza cierra el estudio de Segismundo como personaje en su edición crítica. Ruano de la Haza, Introducción, 49. 


\section{REFERENCIAS BIBLIOGRÁFICAS}

Alvarado Teodorika, Tatiana. "El jardín en el teatro aurisecular. Las comedias mitológicas de Calderón". Actas del XVI Congreso de la Asociación Internacional de Hispanistas (AIH): Nuevos caminos del hispanismo, vol. 2, (2010), 145-165. https://cvc.cervantes.es/literatura/aih/pdf/16/aih 162 049.pdf (consultado el 23 de agosto de 2020).

Aristóteles. Ética a Nicómaco. Editado por Araujo, María, y Marías, Julián. Madrid: Fareso, 1989.

Calderón de la Barca, Pedro. La vida es sueño. Editado por José María Ruano de la Haza. Madrid: Castalia, 2000.

Covarrubias Horozco, Sebastián de. Tesoro de la lengua castellana o española. Madrid: Biblioteca Digital Hispánica, $1611 . \quad \mathrm{http} / / / \mathrm{bdh}$ rd.bne.es $/$ viewer.vm?id $=0000178994 \&$ page $=1$ (consultado el 5 de septiembre de 2020).

Millán González, Silvia Caterina. "Reinos de amazonas en la literatura española de la Edad Media y los Siglos de Oro: arquetipos, género y alteridad". Tesis Doctoral, Universidad de Valencia, 2017. http://roderic.uv.es/handle/10550/60811 (consultado el 28 de octubre de 2020).

Morón Arroyo, Ciriaco. Introducción a La vida es sueño de Pedro Calderón de la Barca, 14-61. Madrid: Cátedra, 1981.

Platón. La República. Editado por Pabón, José Manuel, y Fernández-Galiano, Manuel. Barcelona: Altaya, 1993.

Ruano de la Haza, José María. La puesta en escena en los teatros comerciales del Siglo de Oro. Madrid: Castalia, 2000.

Ruano de la Haza, José María. Introducción a La vida es sueño de Pedro Calderón de la Barca, 7-68. Madrid: Castalia, 2000.

Ruiz Ramón, Francisco. Historia del teatro español. Madrid: Cátedra, 2011.

Sáez Raposo, Francisco. Introducción a Amar por razón de Estado de Tirso de Molina, 13-67. Nueva York / Madrid: Instituto de Estudios Auriseculares (IDEA) / Instituto de Estudios Tirsianos (IET), 2019. https://hld.handle.net/10171/56818 (consultado el 27 de agosto de 2020). 
Sánchez Regueira, Manuela, Introducción a Comedias de Antonio de Solís, 3-42. Madrid: CSIC, 1984.

Serralta, Frédéric. "Nueva biografía de Antonio de Solís y Rivadeneyra", Criticón, 34, 1986, 51-157.

Solís y Rivadeneyra, Antonio de. Comedias de Antonio de Solís, Tomo I. Editado por Manuela Sánchez Regueira. Madrid: CSIC, 1984.

Recibido: 18 de septiembre de 2020

Aprobado: 13 de octubre de 2020 